\title{
A Quality Model for Responsibility Assignment in Repetitive Flow Schooling and Curriculum Processes Associated with a Repairable System of Different Failure Modes
}

\author{
Faten S. M. Abdel-Hameed \\ Bahrain Teachers College, \\ Mathematics, Science and ICT AG \\ University of Bahrain, Bahrain
}

\author{
Salah A. A. Emara \\ Studies and Research Unit \\ University College of Bahrain \\ Kingdom of Bahrain salahemara
}

\begin{abstract}
This paper proposes the use of responsibility modeling as a tool to support the designing of efficient operations of repetitive flow schooling and curriculum processes associated with repairable system of different failure modes. The objective is to develop a deeper understanding of system behaviour as a function of tasks. Based on the assignment of appropriate duration of tasks, we assign daily responsibilities, and expect the line of production to be operating seven hours a day to achieve the production of a number of completed tasks. To find the expected completion line for each activity, we provide twenty- one estimate times for twenty- one employees, and apply task assignment to obtaining the optimal time for completed non-repetitive tasks. Algebraic formulas and the supplementary variable method are used to measure and analyze the different failure modes and repair the tasks of each workstation in the system.
\end{abstract}

\section{Introduction}

Repetitive processes in any organization are described by a mathematical model that uses simplified assumptions of the assignment networks model with time that enables the realities of the organizational systems. These same methods can also be used if it is desired to perform repetitive processes associated with repairable system of different failure modes for educational and curricular activities. We assign twenty- one personnel (employees) to twenty- one jobs (tasks) within the distribution area of an organizational system. The models used to measure the effectiveness of a particular set of assignments of total time to perform a set of operations, and to determine the production rate of each workstation and bottleneck workstation, complementing those results obtained in ([5], [6]). Mathematical formulas are used to measure the availability and unavailability associated with repairable system of different failure modes for each workstation.

\section{Activity Time}

Here, we discuss the detailed design of repetitive flow processes, which focuses on balancing the assignment of work at workstations (WS), and explains the applicability of repetitive flow principles to disconnected flow processes [8], [9], [10], [11].

We apply the assignment model for twenty- one employees to be assigned to twenty- one tasks and a time $t_{i j}$ that is associated with employee i performing task $\mathrm{j}$. Our goal is to minimize the total time of assigning employees to tasks so that each employee is assigned one job and each job is performed. The time required to complete each and every activity is expressed in seconds. Table 1 represents the total enumeration of all matrix possibilities of assigning twenty- one employees on twenty- one tasks. Now we apply the following steps on Table 1 to reach the time-efficient assignment:

Step 1: Subtract the minimum entry in each row from all the entries on that row.

Step 2: Subtract the minimum entry in each column of task-opportunity time matrix from all the entries of that column.

Step 3: Check for optimality: Draw the minimum number of horizontal and vertical lines to cover all zeros in the rows and columns. This can be done in twenty- one lines, or we apply the shuffling for the tasks among the employees, in order get the required time matrix, i.e., we obtain the minimum total time of assigning twenty- one employees to twenty- one tasks so that each employee is assigned one task as given in the diagonal of the following time-matrix as shown in Table 2. 
Table 1. Time matrix of assigning 21 employees to 21 tasks $($ Emp $=$ Employee and $\mathrm{T}=$ task $)$

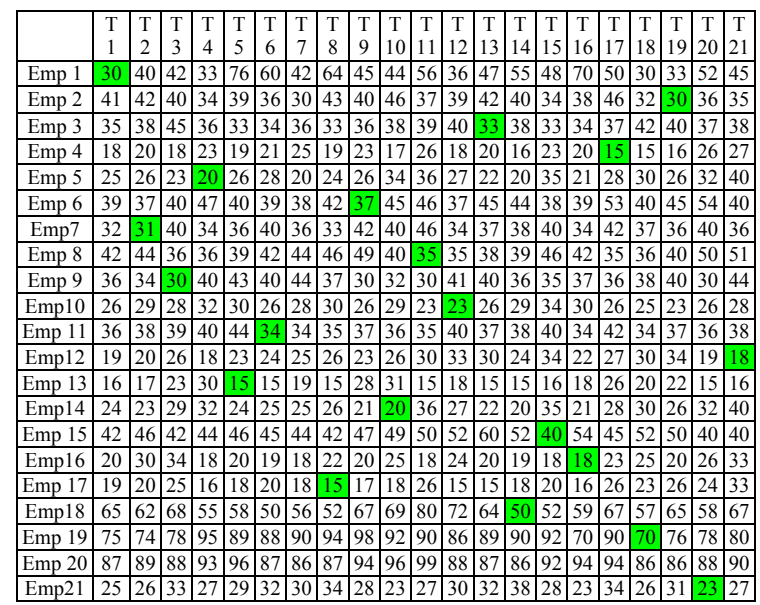

Table 2. Time-efficient assignment of 21 employees to 21 tasks

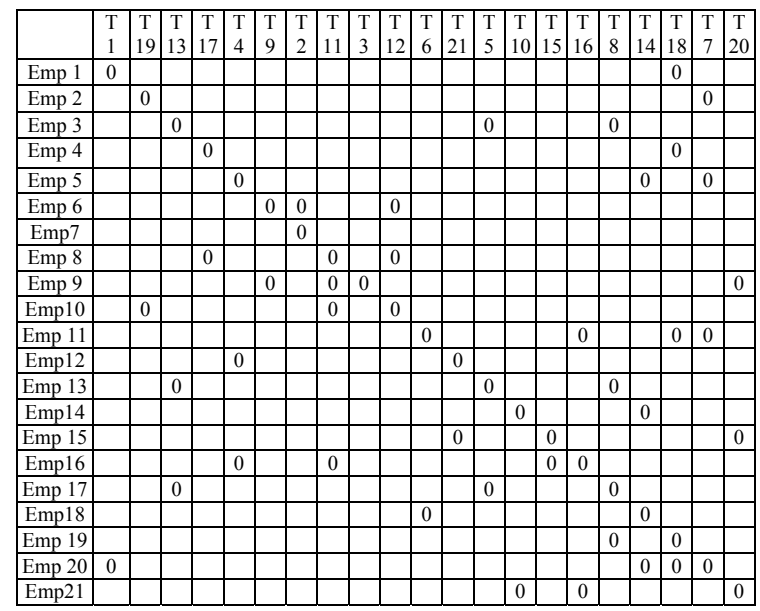

From Table 2 the Employee $\mathrm{i}$ will be assigned to the task j, where $\mathrm{i}, \mathrm{j}=1$ to 21 . From Table 1 , one can see that the optimal time for (Emp 1, Task 1) is $30 \mathrm{sec}$, for (Emp 2, Task 19) is $30 \mathrm{sec}$, and similarly for the rest of employees and the corresponding tasks. Now, we assign the 21 daily tasks to the 21 employees for one day with one task per person per prescribed time, to produce at least 240 tasks altogether. We expect the line of production to be operating 420 minutes each day. At this stage of study each activity will be assigned with an optimal time and predecessor. Table 3 presents the activities, the predecessors and the optimal time $(\mathrm{t})$ for activities as obtained from Tables 1 and 2.

Table 3. Task optimal time for activities

\begin{tabular}{|c|c|c|c|}
\cline { 2 - 4 } \multicolumn{1}{c|}{} & Activity & Predecessor & Optimal time (t) \\
\hline 1 & A & - & 30 \\
\hline 2 & B & A & 30 \\
\hline 3 & C & B & 33 \\
\hline
\end{tabular}

\begin{tabular}{|c|c|c|c|}
\hline 4 & $\mathrm{D}$ & $\mathrm{C}$ & 15 \\
\hline 5 & $\mathrm{E}$ & $\mathrm{D}$ & 20 \\
\hline 6 & $\mathrm{~F}$ & $\mathrm{D}$ & 37 \\
\hline 7 & $\mathrm{G}$ & $\mathrm{D}$ & 31 \\
\hline 8 & $\mathrm{H}$ & $\mathrm{D}$ & 35 \\
\hline 9 & $\mathrm{I}$ & $\mathrm{D}$ & 30 \\
\hline 10 & $\mathrm{~J}$ & $\mathrm{D}$ & 23 \\
\hline 11 & $\mathrm{~K}$ & $\mathrm{E}, \mathrm{F}, \mathrm{G}, \mathrm{H}, \mathrm{I}$, & 34 \\
\hline 12 & $\mathrm{~L}$ & $\mathrm{~J}$ & 18 \\
\hline 13 & $\mathrm{M}$ & $\mathrm{K}$ & 15 \\
\hline 14 & $\mathrm{~N}$ & $\mathrm{~K}$ & 20 \\
\hline 15 & $\mathrm{O}$ & $\mathrm{K}$ & 40 \\
\hline 16 & $\mathrm{P}$ & $\mathrm{K}$ & 18 \\
\hline 17 & $\mathrm{Q}$ & $\mathrm{K}$ & 15 \\
\hline 18 & $\mathrm{R}$ & $\mathrm{K}$ & 50 \\
\hline 19 & $\mathrm{~S}$ & $\mathrm{R}$ & 70 \\
\hline 20 & $\mathrm{~T}$ & $\mathrm{~L}, \mathrm{M}, \mathrm{N}, \mathrm{O}$, & 86 \\
\hline 21 & $\mathrm{U}$ & $\mathrm{P}, \mathrm{D}$ & 23 \\
\hline & & Total (T) & 673 \\
\cline { 3 - 4 } & & & \\
\hline
\end{tabular}

We want to assemble a line to produce at least 240 completed tasks per day and expect the line to be operating 420 minutes each day.

(Working) day $=$ operating time each day

$$
=420 \mathrm{~min}=25,200 \mathrm{sec}
$$

$\therefore$ Maximum cycle time $=\mathrm{C}_{\max }$

$=1 /$ (minimum desired production rate)

$=1 /$ ( 240 completed tasks per day $)$

$$
\begin{aligned}
& =\frac{1 \text { day }}{240 \text { completed tasks }} \text { (substitute from (1)) } \\
& =\frac{25,200 \text { seconds }}{240 \text { completed tasks }}=105 \mathrm{sec} / \text { completed tasks }
\end{aligned}
$$

$\therefore \quad \mathrm{C}_{\max }=105 \mathrm{~second} /$ completed tasks

Theoretical minimum number of workstations $=$ $\left\|\frac{\mathrm{T}}{\mathrm{C}_{\max }}\right\|=\left\|\frac{673}{105}\right\|=\|6.4095\|=7 \mathrm{WS}$

(where $\|$ means round up of any fractional values). The basic idea from constructing the production line is to assign as much work to each workstation (WS) as possible without exceeding $\mathrm{C}_{\max }$. We apply the Ranked Positional Weighted Technique (RPWT) to obtain the actual number of workstations and the actual production per day, where the RPWT is applied to measure the task's importance as a predecessor. From Table 3, we construct a diagram of the precedence relationship among the tasks. Arrows are used to show which 
tasks must precede others. This is shown in the Figure1.

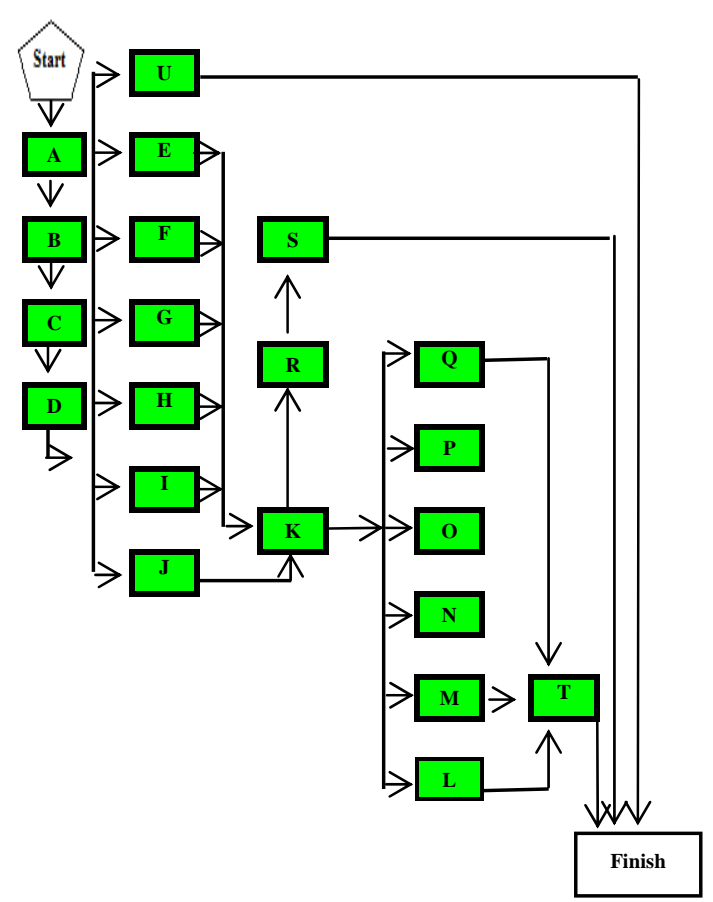

Figure 1. Procedure diagram for the activities

For each task, add up the task time for that task and all the tasks times which follow it directly and indirectly. This value is called the Positional Weight for the task. PW(A) denotes the positional weight for task $\mathrm{A}$, and it is computed from the sum of the task times for the tasks: A, B, C, D, E, F, G, H, I, J, K, L, $\mathrm{M}, \mathrm{N}, \mathrm{O}, \mathrm{P}, \mathrm{Q}, \mathrm{R}, \mathrm{S}, \mathrm{T}, \mathrm{U}$, i.e., $\mathrm{PW}(\mathrm{A})=620$. Similarly we obtain the positional weights for all the remaining tasks as, $\mathrm{PW}(\mathrm{B})=590, \mathrm{PW}(\mathrm{C})=530$, $\mathrm{PW}(\mathrm{D})=497, \mathrm{PW}(\mathrm{E})=380, \mathrm{PW}(\mathrm{F})=403, \mathrm{PW}(\mathrm{G})=$ 397, $\mathrm{PW}(\mathrm{H})=401, \mathrm{PW}(\mathrm{I})=396, \mathrm{PW}(\mathrm{J})=389$, $\mathrm{PW}(\mathrm{K})=246, \mathrm{PW}(\mathrm{L})=104, \mathrm{PW}(\mathrm{M})=101, \mathrm{PW}(\mathrm{N})$ $=106, \mathrm{PW}(\mathrm{O})=126, \mathrm{PW}(\mathrm{P})=104, \mathrm{PW}(\mathrm{Q})=101$, $\mathrm{PW}(\mathrm{R})=120, \mathrm{PW}(\mathrm{S})=70, \mathrm{PW}(\mathrm{T})=86, \mathrm{PW}(\mathrm{U})=$ 23.

Here, we arrange each task according to its positional weight in descending order by selecting the task with largest positional weight and assign it to be the first workstation, and next we select the task with next largest positional weight, then repeat the same for the rest of tasks. i.e., we select A first because it has the largest positional weight, and assign it to workstation $\mathrm{WS}_{1}$ (workstation 1), the second highest (largest) positional weight will be activities: B, C, D, F, H, ... etc.
Table 4. Task optimal times in seconds arranging the positional weights for the activities in descending order

\begin{tabular}{|c|c|c|c|}
\cline { 2 - 4 } \multicolumn{1}{c|}{} & Activity & $\begin{array}{c}\text { Optimal time } \\
\text { (t) }\end{array}$ & $\begin{array}{c}\text { Positional weight } \\
\text { PW }\end{array}$ \\
\hline 1 & A & 30 & 620 \\
\hline 2 & B & 30 & 590 \\
\hline 3 & C & 33 & 530 \\
\hline 4 & D & 15 & 497 \\
\hline 5 & F & 37 & 403 \\
\hline 6 & H & 35 & 401 \\
\hline 7 & G & 31 & 397 \\
\hline 8 & I & 30 & 396 \\
\hline 9 & J & 23 & 389 \\
\hline 10 & E & 20 & 380 \\
\hline 11 & K & 34 & 246 \\
\hline 12 & O & 40 & 126 \\
\hline 13 & R & 50 & 120 \\
\hline 14 & N & 20 & 106 \\
\hline 15 & L & 18 & 104 \\
\hline 16 & P & 18 & 104 \\
\hline 17 & M & 15 & 101 \\
\hline 18 & Q & 15 & 101 \\
\hline 19 & T & 86 & 86 \\
\hline 20 & S & 70 & 70 \\
\hline 21 & U & 23 & 23 \\
\hline & & & \\
\hline
\end{tabular}

Now, we obtain the workstations as:

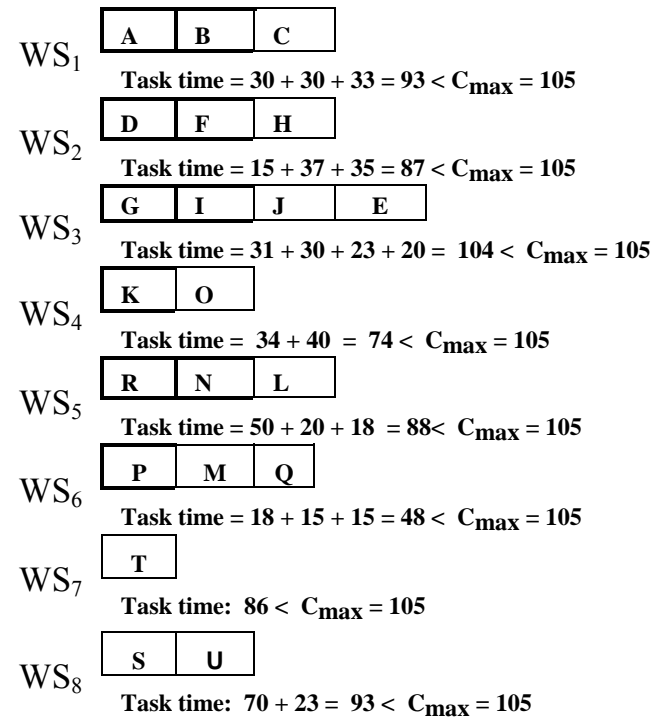

The workstation with longest time $(C=104$ second/ task) is called the bottleneck work-station, obtained at $\mathrm{WS}_{3}$, and the actual production rate for the production line is given by

$$
\mathrm{p}=\frac{1}{\mathrm{C}}=\frac{1}{104 \frac{\text { second }}{\text { task }}}
$$




$$
\begin{aligned}
& \because \quad \text { day }=25,200 \text { seconds } \\
& \therefore \quad \text { second }=\frac{1}{25,200} \text { day }
\end{aligned}
$$

(since the operation time is 420 minutes $=420 \times$ $60=25,200 \mathrm{sec})$.

From (4) and (5) we get the actual rate

$$
\begin{aligned}
\mathrm{p}=\frac{1}{\mathrm{C}} & =\frac{1}{104 \frac{1 \text { day }}{25,200 \text { task }}}=\frac{25,200 \text { task }}{104 \text { day }} \\
& =242.3076 \text { tasks/day }
\end{aligned}
$$

Therefore, the actual rate of production is $\mathrm{p}=$ 242. 3076 tasks/ day, which is greater than the target production rate 240 tasks/ day, since

$$
\text { Actual cycle time } \mathrm{C}<\max \text { cycle time } \mathrm{C}_{\max }
$$

\section{The Efficiency or Percentage Balance of the Production Line}

The efficiency or percentage balance of the production line is obtained by:

Efficiency (percentage balance) of a line

$$
=\left[\frac{\mathrm{T}}{\mathrm{N} \times \mathrm{C}}\right] \times 100 \%
$$

Where, $\mathrm{N}$ is the number of actual workstations. In our case: $\mathrm{N}=8 \mathrm{WS}$ 's, $\mathrm{C}=104 \mathrm{~second} /$ task, and $\mathrm{T}=$ 1232 seconds.

$\therefore$ Efficiency for the production line

$$
=\left[\frac{673}{8 \times 104}\right] \times 100 \%=80.89 \% \text {. }
$$

i.e., the efficiency or percentage balance of the line equals $80.89 \%$, and the capacity wasted (idleness) is equal to $19.11 \%$.

Here, we evaluate the efficiency and idleness for each work station: $\mathrm{WS}_{3}$ is working at $100 \%$, while efficiency $\mathrm{WS}_{1}=88$. 57\%, efficiency $\mathrm{WS}_{2}=82$. $86 \%$, efficiency $\mathrm{WS}_{4}=70.48 \%$, efficiency $\mathrm{WS}_{5}=$ 83. $81 \%$, efficiency $\mathrm{WS}_{6}=45.71 \%$ and efficiency $\mathrm{WS}_{7}=81.90 \%, \mathrm{WS}_{8}=88.57 \%$ with idleness of $: 11.43 \%$, 17.14\%, 29. 52\%, 16. 19\%, 54. 29\%, $18.1 \%$, and $11.43 \%$ for each workstation, respectively.

\section{Repairable Tasks with Different Failure Modes for WS1}

This section presents mathematical model and analysis of repair- replacement for WS1, and with three failure modes: normal, partial failure and total failure. Figure 2 shows the state diagram of a single repairable component with failure modes for WS1. Similar repairable systems are applied for the rest of WS's, related literature may be found in ([1], [2], [3], [4], [7], [12], [13]).

A, B and C: are the operation, partial failure and total failure states, respectively, at time $\mathrm{t}=0$,

$P_{i}(t), i=0,1,2$ : the probability that the system is in the states A, B and C, respectively at time $\mathrm{t}$,

$\lambda, \beta$ and $\mu$ : are the constant failure, repairmenavailability and replacement rates, respectively.

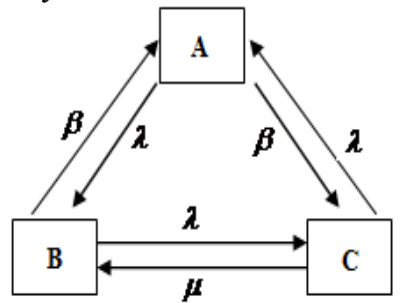

Figure 2. State diagram for a single repairable component with failure modes for WS1

We apply the supplementary variable method to analyze the model; the following differential equations can be obtained under the following assumptions:

$$
\begin{aligned}
& \frac{\mathrm{dP}_{\mathrm{O}}(\mathrm{t})}{\mathrm{dt}}=-(\lambda+\beta) \mathrm{P}_{\mathrm{O}}(\mathrm{t})+\beta \mathrm{P}_{1}(\mathrm{t})+\lambda \mathrm{P}_{2}(\mathrm{t}) \\
& \frac{\mathrm{dP}_{1}(\mathrm{t})}{\mathrm{dt}}=\lambda \mathrm{P}_{\mathrm{O}}(\mathrm{t})-(\lambda+\beta) \mathrm{P}_{1}(\mathrm{t})+\mu \mathrm{P}_{2}(\mathrm{t}) \\
& \frac{\mathrm{dP}_{2}(\mathrm{t})}{\mathrm{dt}}=\beta \mathrm{P}_{\mathrm{O}}(\mathrm{t})+\lambda \mathrm{P}_{1}(\mathrm{t})-(\mu+\lambda) \mathrm{P}_{2}(\mathrm{t})
\end{aligned}
$$

The initial conditions are as follows:

$$
\mathrm{P}_{\mathrm{o}}(0)=1, \mathrm{P}_{1}(0)=\mathrm{P}_{2}(0)=0 \text {. }
$$

Applying the Laplace transforms to (6) - (9) we obtain

$$
\begin{aligned}
& \mathrm{s}_{\mathrm{o}}(\mathrm{s})-\mathrm{P}_{\mathrm{o}}(0)=-(\lambda+\beta) \mathrm{P}_{\mathrm{o}}(\mathrm{s})+\beta \mathrm{P}_{1}(\mathrm{~s})+\lambda \mathrm{P}_{2}(\mathrm{~s}) \\
& \mathrm{s}_{1}(\mathrm{~s})-\mathrm{P}_{1}(0)=\lambda \mathrm{P}_{\mathrm{o}}(\mathrm{s})-(\lambda+\beta) \mathrm{P}_{1}(\mathrm{~s})+\mu \mathrm{P}_{2}(\mathrm{~s}) \\
& \mathrm{s}_{2}(\mathrm{~s})-\mathrm{P}_{2}(0)=\beta \mathrm{P}_{\mathrm{o}}(\mathrm{s})+\lambda \mathrm{P}_{1}(\mathrm{~s})-(\mu+\lambda) \mathrm{P}_{2}(\mathrm{~s}) \\
& \text { On applying the initial conditions }(9) \text { to equations } \\
& \text { (10)- }(11) \\
& (\mathrm{s}+\lambda+\beta) \mathrm{P}_{\mathrm{O}}(\mathrm{s})-\beta \mathrm{P}_{1}(\mathrm{~s})-\lambda \mathrm{P}_{2}(\mathrm{~s})=1 \\
& -\lambda \mathrm{P}_{\mathrm{O}}(\mathrm{s})+(\mathrm{s}+\lambda+\beta) \mathrm{P}_{1}(\mathrm{~s})-\mu \mathrm{P}_{2}(\mathrm{~s})=0 \\
& -\beta \mathrm{P}_{\mathrm{O}}(\mathrm{s})-\lambda \mathrm{P}_{1}(\mathrm{~s})+(\mathrm{s}+\mu+\beta) \mathrm{P}_{2}(\mathrm{~s})=0
\end{aligned}
$$

The solutions for (8)- (10) are

$$
\mathrm{P}_{\mathrm{O}}(\mathrm{s})=\frac{\Delta_{\mathrm{o}}}{\Delta}, \mathrm{P}_{1}(\mathrm{~s})=\frac{\Delta_{1}}{\Delta}, \mathrm{P}_{2}(\mathrm{~s})=\frac{\Delta_{2}}{\Delta}
$$

where

$$
\Delta_{\mathrm{o}}=\mathrm{s}^{2}+\mathrm{s}(2 \lambda+\beta+\mu)+\mu \beta+\lambda^{2}+\lambda \beta,
$$




$$
\begin{aligned}
& \Delta_{1}=\mathrm{s} \lambda+\mu \lambda+\lambda^{2}+\mu \beta, \\
& \Delta_{2}=\mathrm{s} \beta+\beta \lambda+\beta^{2}+\lambda^{2}, \\
& \Delta=s^{3}+s^{2}(3 \lambda+2 \beta+\mu)+ \\
& \quad s\left(\mu \lambda+\lambda \beta+2 \mu \beta+3 \lambda^{2}+\beta^{2}\right)
\end{aligned}
$$

The availability in the steady state of the model is

$$
\begin{aligned}
A=\lim _{s \rightarrow 0} s\left[P_{O}(s)+P_{1}(s)\right]= \\
\\
\frac{2 \mu \beta+2 \lambda^{2}+\lambda \beta+\mu \lambda}{\mu \lambda+\lambda \beta+2 \mu \beta+3 \lambda^{2}+\beta^{2}}
\end{aligned}
$$

and the unavailability of the model is

$$
\begin{aligned}
\mathrm{UA}=\lim _{\mathrm{s} \rightarrow 0} & \mathrm{sP}_{2}(\mathrm{~s})= \\
& \frac{\lambda \beta+\beta^{2}+\lambda^{2}}{\mu \lambda+\lambda \beta+2 \mu \beta+3 \lambda^{2}+\beta^{2}}
\end{aligned}
$$

Special case: If $\lambda=\mu=\beta=0.5$, then $\mathrm{A}+\mathrm{UA}=1$.

\section{Conclusion}

The main focus of the study was to describe the quality methodology and algorithm for solving a repetitive processes problem based on the assignment of appropriate duration of responsibilities for school and curriculum improvement. The interaction between successive activities was obtained in order to control those processes for the sake of achieving the desired efficiencies for the production line. We applied the repairable system with different failure modes and obtained the measure of the availability and the unavailability of the work-stations.

\section{References}

[1] B. S. Dhillon, "Partial and Catastrophic Failure Analysis of a Complex System", Microelectronics and Reliability, Vol. 19, 1979, 349- 350, Pergamon Press, UK.

[2] B. S. Dhillon, "Two Failure Modes System with Cold Stand-By Units, Microelectronics and Reliability”, Vol. 18, 1978, 251- 252, Pergamon Press, UK.

[3] B. S. Dhillon “Availability of Repairable System with Non-repairable Stand-By Units,Microelectronics and Reliability”, Vol. 15, 1978,561- 562, Pergamon Press, UK.

[4] B. S. Dhillon, "Analysis of Three-State System with Two Types of Components, Units, Microelectronics and Reliability”, Vol. 15, 1976, 245- 246, Pergamon Press, UK.

[5] Faten S.M. Abdel-Hameed and Salah A.A. Emara, "Assignment of Appropriate Duration of Responsibilities that woukld Increase the Efficiency of Repetitive Flow
Processes for School and Curriculum Activities", Proceedings of CICE-2011, Toronto, Canada.

[6] Faten S.M. Abdel-Hameed and Salah A.A. Emara, "Design of Repetitive Processes for School and Curriculum Improvement", Proceedings of CICE-2010, Toronto, Canada.

[7] M. Hajeeh, “Analysis of Repairable System Subjected to Multiple Modes of Failure“, Economics Quality Control, Vol 19, 2004, No. 2, 167- 173

[8] J. Heizer and B. Render, "Operations Management", $8^{\text {th }}$ edition, Pearson, USA, 2006.

[9] J. Heizer and B. Render, "Operations Management", Flexible Version, Pearson, Prentice Hall, USA, 2005.

[10] F.S. Hillier and M.S. Hillier, "Introduction to Management Science, A Modeling and Case Studies Approach with Spread Sheets", McGraw Hill, USA, 2003.

[11] R.S. Russell and B.W. Taylor III, "Operations Management", $4^{\text {th }}$ edition, Prentice Hall, Pearson Education, Canada, USA, 2003.

[12] Salah A.A. Emara and Faten S.M. Abdel-Hameed, "Analysis of a Repairable System Subject to Different Failure Modes", Proceeding of The International Conference and Exhibition on Knowledge-Based Business, Industry and Education, KBIE-2011, Kingdom of Bahrain, Ritz Carlton, Ghazal Ballroom, 8- 10 January 2011

[13] S. Emara and K. El-Said, "Repairable System with Different Failure Modes”, WCNA'92 Proceedings of the First World Congress on Nonlinear Analysts, Florida, USA, Vol. II, 1995. 